Revista Iberoamericana, Vol. LXXII, Núm. 214, Enero-Marzo 2006, 139-153

\title{
“CONOCER Y SER CONOCIDO”: IDENTIDAD CULTURAL, MERCADO Y DISCURSOS GLOBALES EN TRES REVISTAS LATINOAMERICANAS DE ENTRE SIGLOS
}

\author{
POR \\ Alejandro Mejías López \\ Indiana University
}

En enero de 1886, el periódico neoyorquino El Latino-Americano dedicó su página editorial a dos asuntos cuya conexión, quizás no aparente a primera vista, merece una relectura. Empezaré por el segundo de ellos, el más breve y situado en el centro de la página bajo el título “¿Quiénes son los americanos?”. En él, se denuncia una entrevista publicada en The New York World, "ese jigante [sic] del moderno periodismo" (152) con el ex ministro estadounidense Wallace, quien proponía que Estados Unidos simplificara su nombre al de “América”, a lo que los editores respondían:

[Q]ueda todo el Canadá, México, Centro y Sur-América y las Antillas, cuyos habitantes son americanos igualmente con los ciudadanos de los Estados Unidos de Norte América. Es verdad que por conveniencia se llaman a menudo “americanos" los ciudadanos de esta república colosal, pero es muy natural que nosotros, los hispano-americanos, tengamos el mismo derecho a ese nombre. (152)

Frente al coloso del norte, este "nosotros” anticipa, como veremos, la formulación martiana de "nuestra” América.

El otro editorial, el primero, situado en la parte inferior izquierda de la página, celebra la incorporación de Japón a la "civilización occidental” y es titulado "Conocer y ser conocido”. En él, cuentan los editores cómo Japón, además de incorporar avances tecnológicos, ha tomado medidas que "indican una maravillosa tendencia al progreso":

Uno de éstos es haber enviado un crecido número de japoneses, quienes actualmente se hallan trabajando, cada uno en su oficio, en el edificio del Madison Square Garden. El público norteamericano acude, pagando una entrada módica, a ver con sumo interés la habilidad con que aquellos fabrican tantos objetos primorosos que luego se venden en todo el mundo con grande estimación. Eso conduce a que se conozca aquí a los japoneses y por consiguiente se aumenten las relaciones con su país y así su riqueza y el bienestar del pueblo. Este es uno de los sistemas empleados por el Japón para hacerse conocer. (152)

Dentro del más puro liberalismo, cultura, mercado, ideas y progreso parecen fluir todos en armonía. El intercambio de información y mercancías son parte imprescindible de una modernidad en la que tan importante es conocer como ser conocido, consumir tanto 
como producir, en lo económico y en lo cultural puesto que no solo están directamente relacionados, sino que el segundo llevaría al primero.

Al poner ambos editoriales en la misma página, el periódico invita a leerlos en diálogo. La entrevista a Wallace aparecía en The New York World, un “mundo” de cuyo mapa Wallace eliminaba tres cuartas partes del continente, absorbiéndolas con un movimiento imperial. La modernidad latinoamericana, la existencia misma de Latinoamérica, podía desaparecer en la simple enunciación del discurso imperial de Estados Unidos, su modelo paradójico de democracia liberal. La solución de El Latino Americano estaría en el otro editorial: “conocer y ser conocido”, esto es, no sólo consumir sino producir conocimiento porque, como diría Martí poco más tarde, "por el respeto, luego que [el vecino] la conociese, sacaría de [nuestra América] las manos” (Nuestra América 22). En los juegos de poder que la modernidad traía consigo, el ámbito del conocimiento y del discurso, el acto mismo de nombrar al otro, podía tener y tenía consecuencias materiales, de ahí la inscripción del "nosotros, los hispano-americanos" frente al discurso colonizador de Wallace. Un acto de escritura y representación propia con el que insertarse en los mapas de la modernidad.

En este ensayo me interesa explorar este “conocer y ser conocido” como la constitución de un paradigma discursivo latinoamericano en el período de entre siglos mediante el cual los intelectuales toman conciencia de la importancia de los discursos representacionales en un momento en el que las condiciones materiales, económicas, y culturales del siglo xIX están consolidando lo que ya aparecía como un nuevo orden mundial o global. Me voy a centrar en el ámbito de las publicaciones periódicas de carácter cultural editadas y publicadas fuera de Latinoamérica en los que eran percibidos como centros mismos de la modernidad, Nueva York y París. Dada la naturaleza de este ensayo era imposible cualquier pretensión de exhaustividad por lo que he tomado tres publicaciones como representativas de tres momentos del período, desde la década del ochenta hasta la segunda década del siglo xx: El Latino-Americano de Nueva York (1884-1886), en la que quizás pongo más énfasis por ser la única hasta ahora desconocida, la Revista Ilustrada de Nueva York (1886-1898), una de las más prestigiosas revistas del Modernismo, y la Mundial Magazine de París (1911-1914), editada por Rubén Darío, la más sofisticada y elaborada de las tres. En concreto, me interesa destacar cómo en estas publicaciones identidad, cultura, mercado y globalización se constituyen en elementos íntimamente conectados, por encima de lo paradójico, con una estrategia de alcance político: el enfrentar la colonización material y cultural de los centros de poder. Desde un lugar fuera, estas revistas, y la prensa como institución en general, parecen ocupar un espacio discursivo privilegiado desde el que apelar a la unidad y construcción de la identidad latinoamericana, escribirse a sí misma y proyectarse dentro del centro mismo de la modernidad: conocer y ser conocido. Quiero proponer, a su vez, una relectura de la relación entre periodismo, literatura, cultura y política que ayude también a recontextualizar textos claves de la modernidad latinoamericana como "Nuestra América” de Martí, texto también marcado por el "afuera” de su lugar de enunciación. 
ESCRIBIR LATINOAMÉRICA DESDE FUERA:

El Latino-Americano, La ReVISta ilustrada de Nueva York y Mundial magazine

El Latino-Americano fue un periódico publicado en español en Nueva York entre los años 1884 y 1886. Considerado perdido por mucho tiempo, quedó en la memoria literaria asociado al nombre de José Martí quien publicó en él su única novela Amistad funesta. ${ }^{1}$ Salía de forma quincenal y, aunque lo literario supone un alto porcentaje de su contenido, éste incluía una variedad de áreas, tal como indicaba su título completo: "El Latino Americano. Periódico para familias. Literatura, ciencias, artes, viajes, música, teatros, modas, conocimientos útiles, intereses generales”. Esto nos da ya una indicación del tipo de lectores al que iba dirigido, de clase media con un nivel de educación medio alto. El mismo José Martí explica las normas del periódico en el prólogo a su novela, en la que no debía haber "nada que no fuese del mayor agrado de los padres de familia y de los Sres. sacerdotes. Y había de ser hispano-americana” (110). Se trataba, pues, de un emergente público latinoamericano, ya no concebido exclusivamente en términos masculinos sino familiares lo que venía a significar la inclusión de un lectorado femenino, al que se apela no sólo en el tipo de contribuciones literarias, sino también en artículos divulgativos y en el "Suplemento de Moda” que publicaba. Con respecto a su circulación, es imposible saber el número de suscriptores y de tiradas que llegó a tener en sus dos años de existencia. A juzgar por referencias diversas a su elevado número de lectores, a la abundancia de cartas recibidas felicitándolo, a las agencias de venta desparramadas por toda Latinoamérica, parecería que el periódico gozaba de buena salud económica y con un lectorado importante, aunque cuán importante es difícil saber.

Además de contribuciones literarias narrativas y poéticas, el periódico incluía artículos de opinión y de divulgación sobre historia, medicina, e higiene, así como sobre aspectos culturales o eventos de diferentes partes del mundo. A ellos se sumaban secciones de juegos y concursos destinados a aumentar el número de suscriptores así como noticias breves dedicadas al comercio y páginas de avisos comerciales. Todo lo cual confirma la idea de un público lector burgués de nivel económico y cultural medio y alto, unido por afinidades estéticas, sociales y económicas que iban más allá de la nacionalidad. No obstante, si no la nación, el ámbito lingüístico, geográfico y cultural sí que eran elementos constituyentes de la comunidad de lectores a los que apelaba el periódico neoyorquino desde su mismo nombre. Como le indicaban a Martí, El Latino-Americano se piensa parte de una comunidad de escritores y lectores, intelectuales y comerciantes, hombres y mujeres, hispanoamericanos, constitutivos del "nosotros" con el que se enfrentaba a la agresión verbal de Wallace. Se trata de una identidad unificadora construida sin cesar, desde las contribuciones literarias hasta los editoriales desde los que se exalta "el espíritu de invención” (Apuntes 24) y la profusión de ideas generadas en Latinoamérica. Resulta importante destacar que a pesar de ser publicado en Nueva York por miembros de la comunidad hispana, la comunidad que a un tiempo construye y apela tiene fronteras geográficas que excluyen a Estados Unidos: “[la] Patria [de El Latino-Americano] se linda

\footnotetext{
${ }^{1}$ En 1997 encontré en la Biblioteca Pública de Nueva York algunos números de El LatinoAmericano de los años 1885 y 1886 que pedí poner en microfilm, entre los cuales se encuentran las últimas entregas de la novela martiana. Mi análisis está basado en estos números.
} 
por el norte con Tejas y termina en el Cabo de Hornos y con cariño fraternal abraza a las Islas que hacen bellas nuestros mares” (Política 72). Patria como nación ha dejado paso a la patria como comunidad continental cuya soberanía debe ser además de política, cultural.

Esta cultura es entendida también como objeto cuyo consumo refuerza los lazos comunitarios. Un caso ilustrativo se encuentra en el lugar paradójico que política y religión ocupan en el periódico donde quedan prohibidas como objeto de debate pero fomentadas como iconos culturales, símbolos consumibles de la comunidad. En el editorial del primero de noviembre de 1885 titulado "Política y religión” se asegura a los lectores que estas no tienen cabida entre sus páginas tanto para no ofender a ningún lector como porque "en El latinoamericano nunca aparecerá nada que pueda incitar por un momento al labrador a que deje el harado [sic] y tome el arma en la mano" (72). Anterior al caso Wallace, el editorial alaba el modelo estadounidense, la actitud de cuyos ciudadanos [“Oh, yo no leo la parte política, no quiero calentarme la sangre. Leo todo lo tocante a industrias, progreso del país, desarrollo de negocios nuevos” (72)] determinaría el tipo de periodismo deseable para los editores. En otras palabras, revolución y mercado no son compatibles y, para el periódico, como en el editorial sobre Japón, es en la unión e intercambio de mercado y cultura donde reside el progreso. Cultura e ideas deben crear lazos, no abrir grietas, no sólo por el bien de la comunidad local sino por el bien de la comunidad global: “debemos trabajar en pro de la Paz universal” (72). Esta insistencia en no tratar temas que puedan ofender o incitar a la disputa ciertamente no es nueva ni original a El Latino-Americano pues se puede encontrar con variantes en muchas publicaciones periódicas decimonónicas latinoamericanas. Lo que me interesa destacar aquí es la dimensión transnacional que toma en esta revista y su vinculación a una emergente conceptualización del progreso en términos “universales”. La identidad latinoamericana quiere ser insertada dentro de un mapa global de una modernidad dominada y determinada por la coexistencia económica y cultural.

Paradójico podría parecer, pues, que una de las principales estrategias publicitarias del periódico sea regalar a quienes se suscriban al segundo año una de dos oleografías, o de Simón Bolívar ("un elegante retrato del que figura primero en la historia de nuestra raza como pueblo libre”) o de la Virgen de Guadalupe (“Con el objeto de satisfacer a todo el mundo [...] hemos obtenido el privilegio de ofrecer [...] una espléndida reproducción oleográfica del famoso cuadro de Nuestra Señora de Guadalupe” [Contraportada]). No obstante, esta paradoja es sólo aparente. Tanto Bolívar como Guadalupe son ofrecidos con un carácter simbólico de cohesión, imágenes unificadoras cultural e incluso económicamente en tanto las figuras del "libertador" y la "madre” crean lazos con la comunidad más allá de las diferencias de clase. Bolívar y Guadalupe son signos que apelan a una identidad cultural al mismo tiempo que es objetificada, convertida en objeto de consumo. Son los suscriptores, concebidos como clientes o consumidores, quienes mandan y es en el acto mismo de consumir objetos culturales que se refuerzan los lazos de la comunidad transnacional. ${ }^{2}$

\footnotetext{
${ }^{2}$ Este proceso que, como veremos, va a estar muy presente, aunque de otro modo, en Mundial Magazine podría leerse en relación con la "interpretive community of consumers" (43) de la que habla García Canclini a partir de la globalización. Sería un fenómeno que se iniciaría en cierto grado a fines del XIX.
} 
En 1886, año en que El Latino-Americano dejó de publicarse, la que antes fuera Revista Mercantil de Nueva York pasó a llamarse Revista Ilustrada de Nueva York y habría de convertirse en una de las revistas culturales más importantes de la siguiente década. Aunque tampoco se tienen números exactos, la Revista Ilustrada llegó a tener al parecer una amplia tirada, quizás oscilando entre los nueve mil de 1892 y los siete mil quinientos de 1897 en Latinoamérica (Chamberlin 11-12), circulando "no solo en las grandes ciudades, sino en las poblaciones de segundo y tercer orden de todo Hispano-América" (citado en Chamberlin 5). El tipo de lector es similar al descrito anteriormente, clase media con un nivel medio y alto de educación y de poder adquisitivo.

La Revista Ilustrada se concibe a sí misma como una "publicación de ancha base, de gran espíritu, genuinamente americana, que les sirva a todos por igual en su despertar enérgico a la vida colectiva” (citado en Chamberlin 4), creando y apelando así a una comunidad en la que la identidad cultural hispanoamericana es el factor de cohesión en el momento en que esta comunidad debe “despertar a la vida colectiva”, esto es, incorporarse al mundo concebido como totalidad, utilizando un lenguaje afín al que usaría Martí en “Nuestra América” publicada por primera vez en las páginas de esta revista. Un cambio importante en la Revista es expandir esta comunidad imaginada de lectores a toda la "raza hispánica”, esto es, el incluir de facto a España dentro de las fronteras hispanoamericanas, en un movimiento pan-hispánico que será uno de los elementos definidores del modernismo, estética a la que la Revista se ve pronto asociada. Entre sus colaboradores estaban muchos de los más relevantes escritores y escritoras del momento en América Latina y España como Darío, Díaz Mirón, Gutiérrez Nájera, Martí, Palma, Pardo Bazán, Juan Valera, Sanín Cano y Amalia Puga. Aunque la mayoría de sus lectores se encontraran geográficamente en Latinoamérica, de la que España viene a ser curiosamente casi un apéndice, esta comunidad, no obstante, tiene miembros también en Estados Unidos, Filipinas, Francia y Tánger. Sus campañas publicitarias y de captación de lectores son semejantes a las que hiciera El Latino-Americano y, al igual que éste, apuesta por una política editorial de unidad, "que sirva a todos los gustos y profesiones, sin ofender a ninguno” (citado en Chamberlin 7).

Esta revista también nace con la intención de sumarse a las publicaciones modernas ("magazines”) de vocación transnacional: "con el carácter de verdadero magazine que sigue paso a paso todas las evoluciones de la actividad humana, dará cuenta exacta de los acontecimientos de importancia que ocurran en todas las partes del mundo" (citado en Chamberlin 4). Se acentúan muchos de los principios y actitudes delineadas en El LatinoAmericano, su vocación "mundialista”, su eclecticismo de opinión y su deseo de insertar a Latinoamérica como una entidad cultural dentro del nuevo marco mundial, su deseo de hacer al discurso "hispánico" partícipe de la red textual global. Esto se hace más urgente conforme la revista va enfrentándose a movimientos imperiales que entran en conflicto con sus postulados. En su inicio en 1886, la Revista Ilustrada se hace abanderada del progreso, la industria y el comercio tanto como las artes y la literatura, en una misión que quiere incorporar la comunidad hispanoamericana a la modernidad universal, para lo cual la revista no duda, como lo hiciera El Latino-Americano, en proponer a Estados Unidos como modelo. No obstante, si aquél tuvo que luchar con actitudes imperiales como la de Wallace, la Revista Ilustrada va a tener que reaccionar al progresivo imperialismo 
norteamericano en la década de los noventa que culminaría con la guerra del 98. Es por ello que, coincidiendo con el llamado de Martí en “Nuestra América”, ya en 1891 la revista insiste en la importancia de la creación de discursos propios y, si bien comparte el deseo de dar cabida a todas las opiniones sin “ofender a ninguno”, esta actitud parece tener aquí un propósito más abiertamente político que su antecesora, y quiere convertirse en "poderoso torna voz para los más escogidos miembros de la gran familia hispanoamericana que, por desdicha, no ha ocupado hasta hoy este palenque sino para traducir y exagerar dolorosas disidencias cuya imprudente prolongación y criminal envenenamiento comprometerían a la larga superiores intereses comunes a toda la raza” (8, cursivas son mías). Lejos de una oposición entre identidad cultural y modernidad material, estos intereses comunes suponen la importancia de la producción intelectual y cultural como arma de progreso. Estados Unidos deja pronto de ser el modelo para la integración a la modernidad para convertirse en su más peligroso obstáculo; es por ello que el "ser conocido" se vuelve una necesidad urgente para no ser borrados del mapa simbólico de Wallace y, con ello, borrados del mapa moderno:

En presencia de la [raza] anglosajona, que por su superioridad industrial indiscutible nos menosprecia, y por cálculo nos espía en cada una de nuestras caídas, españoles de América y de España deben aparecer unidos, siquiera sea en el terreno literario, mantener sus tradiciones, perseguir sus propios ideales, y afirmar en este nuevo mundo revelado a la civilización cristiana, la parte de influencia que de derecho le corresponde. (citado en Chamberlin 8, cursivas son mías)

La conciencia de la creación de un nuevo orden mundial (“este nuevo mundo”) tanto económico como discursivo parece indiscutible, un mundo "revelado", como en los textos bíblicos, por el poder de la palabra. Con ello, La Revista Ilustrada quiere desvelar que en el binomio conocer y ser conocido quien controla el discurso controla el poder y, por tanto, convierte en su programa ideológico la integración del discurso latinoamericano como generador de conocimiento y no sólo como su objeto. Sin duda que para llevarlo a cabo tuvieron que homogeneizar, que erradicar las diferencias y hacer frente común en un proyecto que, al fin y al cabo, era producto de una élite intelectual y económica. ${ }^{3}$ A cambio de ello, los intelectuales de la revista creían armarse para un nuevo orden global que también era orden textual, en el que Latinoamérica debía participar en igualdad de condiciones y en el que el silencio latinoamericano vendría a ser cómplice de la colonización discursiva de otros, objeto de una representación destinada a perpetuarlos como pueblos atrasados, incapaces de subirse al tren de una modernidad en la que no eran agentes sino pacientes y, por tanto, susceptibles de ser colonizados a otro niveles. Dando un paso más allá que El Latino-Americano, la Revista elige mostrar a su comunidad como una sociedad ya en cambio, pionera de ciertas actitudes modernas, como en la defensa en

\footnotetext{
${ }^{3}$ Sobre la construcción de una comunidad transnacional por una élite culta en las revistas internas del Modernismo, véase el excelente análisis de Gerard Aching (146-7) con cuyas conclusiones, no obstante, estoy en desacuerdo al volver a redundar en la idea de aquél como "capable of producing only imprecise or inferior copies of European cultural artifacts and signs” (153).
} 
1890 de la participación intelectual de la mujer a propósito de la escritora peruana Amalia Puga:

\begin{abstract}
Más de una vez hemos leído con indignación en periódicos extranjeros, que la mujer de nuestra América vive apartada del todo de la vida intelectual, que en la ignorancia vegeta y en estéril misticismo se consume. A tales aseveraciones vamos nosotros a oponer la verdad práctica y ya se verá cómo saben presentarse ante el mundo las americanas para figurar digna y altivamente en la escogida legión de los que viven del pensamiento y del espíritu y van alumbrando a la humanidad con sus luces. (6)
\end{abstract}

No son, pues, las propias prácticas sino los discursos ajenos los que presentan, escriben, a la comunidad hispanoamericana como ajena al progreso. En este caso, la participación de la mujer no tiene que cambiar ni copiar otros modelos, puesto que ya se encuentra a la vanguardia del progreso, “alumbrando a la humanidad” el camino.

Esta defensa de la mujer, tantas veces representada como alegoría del continente por la imaginación colonial, podría leerse como una nueva vuelta de tuerca a ese imaginario. Leído así, para los editores de la Revista, Latinoamérica, como la mujer latinoamericana, no vegeta en la "ignorancia” y "el misticismo”, según quieren representarla estrategias discursivas colonizadoras para justificar intervenciones en nombre de una modernidad no alcanzada, sino que se auto representa a la vanguardia de dicha modernidad. Al igual que el "ser conocido" de El Latino-Americano, la Revista Ilustrada parece proponer lo que Martí defendía en sus páginas: "las armas del juicio [...] vencen a las otras. Trincheras de ideas valen más que trincheras de piedra" ("Nuestra América” 11). Este progresivo interés por la relación entre representación y globalización va a culminar en el título mismo de la revista de Darío una década más tarde.

Ya en pleno siglo xx, en 1911 y en París, comienza la publicación de otra importante revista del modernismo, Mundial Magazine, financiada por los hermanos Guido, dos capitalistas uruguayos, quienes reclutaron a Rubén Darío para ser su editor. El Mundial Magazine fue una revista aún más elaborada y cuidada con una importante calidad gráfica de dibujos y fotografías así como de calidad del papel y de diseño. ${ }^{4}$ Desde su mismo título, apela a su carácter transnacional, capitalizando el imaginario de la contemporaneidad del mundo. No obstante, al igual que sus antecesoras neoyorquinas, Mundial Magazine se quiere situar en el intersticio entre lo universal: "La actualidad universal, en industria, comercio, ciencias, artes, vida teatral, modas, etc. será atendida con singular dedicación e interés por aptos colaboradores” (1:5) y lo regional: “Las Repúblicas hispano-americanas serán objeto de nuestro particular cuidado, así como España; y será principalmente con elementos propios como llevaremos a cabo nuestras tareas” (1:5), esto es, entre lo global y lo local.

Es particularmente importante la insistencia en lo actual, llevada más allá de los límites geográficos en su énfasis en la contemporaneidad del planeta, efecto del isocronismo

\footnotetext{
${ }^{4}$ La revista hace continuo hincapié en la alta calidad de su formato, tanto textual como gráfico: “una publicación que en lengua castellana no tendrá rival por su presentación tipográfica y artística y por lo nutrido y vario de su colaboración literaria” (1:5).
} 
que destacaba Ángel Rama como definidor de la cultura finisecular (Rubén Darío 42). ${ }^{5}$ El sintagma “actualidad universal”, la confluencia de todos los tiempos en un solo tiempo, apunta a la coincidencia caléndrica que Benedict Anderson identifica como fuente de asociación a la hora de imaginar la comunidad mediante la prensa: "the steady onward clocking of homogeneous, empty time [within which] 'the world' ambles sturdily ahead” (33). Esto cobra particular importancia ya que es a una doble comunidad a la que apela Mundial desde sus páginas: la "comunidad” hispano-americana, dentro de la "comunidad" universal. La revista, pues, incluye secciones sobre los países latinoamericanos y secciones con la "actualidad" de diversas partes del mundo. Esta idea de la simultaneidad de la actualidad se ve incrementada también de manera gráfica. La revista dedica una sección llamada “crónica mundial” a informar sobre noticias y eventos de África, China, Japón, o Francia, siempre completando la sección con fotografías ilustrativas. En el primer número de la revista, por ejemplo, el de mayo de 1911, en las páginas 62 y 63 se encuentran noticias sobre: el avance del feminismo “en el mundo entero” a propósito de la noruega Anna Rogstadt, primera mujer diputada (con fotografía); un viaje del presidente francés a Túnez; la Revolución Mexicana; un juicio a la Camorra italiana, un túnel en los Alpes (con fotografía); una rebelión en Guinea (con fotografías); y un nuevo gobernador en Argelia. Aunque desde una perspectiva actual no parezca evidente, a principios de siglo la percepción de inmediatez de la información debía ser notable y era aumentada por la imagen; ambas, pues, estaban al servicio de crear en la comunidad lectora la convicción de moverse en un nuevo tiempo global. La coincidencia caléndrica sale de los límites de la comunidad cultural y se expande a la comunidad mundial apelada desde el título de la revista. Una revista mundial que, no obstante, está escrita en castellano, incrementando así aún más la percepción de universalidad de la comunidad lingüística.

Esta comunidad lectora tiene las mismas características que las mencionadas anteriormente. De nuevo, no se sabe con certeza el número de suscriptores ni la circulación que alcanzó, aunque, a juicio de Ana María Hernández, quien se basa en alusiones hechas en la revista así como en cartas entre los editores, debió ser muy elevada. Como la Revista, Mundial se vendía en toda Latinoamérica y España, así como en Filipinas, EE.UU. y Francia. Pero la revista de Darío expandía además sus agentes de publicidad a Gran Bretaña, Alemania, Suiza e Italia. La revista debió alcanzar pronta popularidad en el país anfitrión en el que patrocinaba actos literarios en los que participaban personalidades francesas (Hernández 287). Las técnicas de captación de suscripciones incluían las usadas con anterioridad por otras revistas, además de otras más innovadoras como el viaje promocional. Efectivamente, con el fin de promocionar la revista, los hermanos Guido convencieron a Rubén Darío de realizar una gira por América, gira que aparece anunciada como conmemoración al primer año de la revista y que fue cubierta por un corresponsal y un fotógrafo. Ya el hecho de que Darío aceptara la propuesta de ser director de la revista había supuesto un aval importante para los hermanos Guido, quienes se valieron de la reputación y fama internacional del escritor tanto para atraer el interés de los suscriptores como el respeto intelectual para la que aspiraba a ser una gran revista cultural. Por otro

\footnotetext{
${ }^{5}$ Rama ya apuntaba con lucidez al doble movimiento entre lo universal y lo local de los intelectuales modernistas. Véase también "La ciudad politizada" en La ciudad letrada.
} 
lado, el viaje como epítome de una actividad moderna de acercamiento de las distancias reforzaba el carácter transnacional de la revista mientras estrechaba la unión entre ésta y su comunidad lectora. ${ }^{6}$

En Mundial Magazine, además de esta convivencia entre lo local y lo global, se desarrolla, como en sus antecesoras, una línea de continuidad entre lo intelectual y lo comercial. Dentro de los colaboradores literarios, periodísticos y gráficos de la revista está un gran número de los intelectuales del momento a ambos lados del océano, la mayoría de ellos asociados al modernismo. En París, capital cultural de la modernidad, Darío anunciaba su deseo de crear en Mundial "un órgano parisiense del pensamiento hispanoamericano” (citado por Hernández 28). De hecho, una de las obligaciones contractuales de Darío con los hermanos Guido era la de “conseguir para cada una de estas revistas [Mundial Magazine y Elegancias (suplemento de moda)], la colaboración de las personalidades literarias, artísticas, científicas, etc. más destacadas en los países hispanoamericanos y en España” (citado en Hernández 17). Hay una clara intención de hacer de la revista un "showcase" de la intelectualidad hispánica en el corazón mismo de la intelectualidad moderna de Occidente.

“Pensar es servir” y “crear es la palabra de pase de esta generación”, había dicho Martí en "Nuestra América”. Este énfasis en la creatividad y el pensamiento pasa también en Mundial por establecer ciertas alianzas con el mercado, no sólo en el número de suscriptores sino también en la relación que la revista establece con la publicidad. La revista llama la atención de los lectores a la sección comercial como componente esencial de aquella:

Bajo un aspecto artístico y recreativo hemos querido presentar las casas o artículos que por su reputación mundial y su seriedad o bondad acreditada, merecen la mayor atención y toda la confianza del comprador. En el terreno de los negocios, como en el dominio de la literatura, de las ciencias y de las artes, las invenciones y perfeccionamientos tienen por efecto revolucionar a menudo la fabricación y la presentación de los artículos diversos que consumimos y que son el resultado de la gran vida económica de los países productores. (109)

La sección publicitaria está marcada por un formato “artístico y recreativo” porque, según la revista, los negocios son también un acto creador y revolucionario. Se plantea aquí una analogía que funciona en dos direcciones: si el mercado es como el arte, las letras y la ciencia por lo que tiene de creador, también es cierto lo inverso y, por tanto, el arte y la ciencia son productores de objetos de consumo. Dentro de un discurso simultáneamente

\footnotetext{
${ }^{6}$ Los viajes son tema recurrente en la revista, particularmente los asociados a las nuevas tecnologías y medios de transportes como el aeroplano. Tales son los casos del viaje en avión por Europa de des Moulinais en 1913, a propósito del cual Mundial publica una carta del aviador enviada en exclusiva a la revista con mapas de ruta y fotografías; y los del aviador argentino Jorge Newberry, conseguidor del record mundial de altura en 1914 y cuya fotografía autografiada y dedicada a Mundial publicaba éste en el número de abril de 1914. Ocasiones y exclusivas como éstas eran también fuente de publicidad para la revista y redundaban en la proyección de una publicación a la vanguardia; en la dedicatoria de Newberry, por ejemplo, escrita tras batir el récord, se lee: “A la revista Mundial que ha batido también el récord de altura, gráfica y literariamente” (575).
} 
modernizador y modernista, ${ }^{7}$ ambos ámbitos son presentados como representantes del progreso. Por último, si los negocios son indicativos de la salud económica de un país, artes, ciencias y letras deben serlo de su vida intelectual; finalmente, lo uno supone lo otro.

Esta alianza entre cultura y mercado, que como hemos visto se vuelve un elemento definidor de las revistas finiseculares y que cobra un carácter particularmente interesante en la Mundial Magazine, hay que entenderla más allá de lo paradójico. Según afirma Susana Rotker, "el carácter comercial del periodismo era, en aquel momento, facilitar el comercio, no sólo por el rentable espacio ocupado por los avisos, sino porque gran parte de la información se refería a la actividad mercantil y exportadora-importadora. Hasta el propio Martí tuvo que entre 1883 y 1884 redactar avisos para el diario Las Américas” (1023). Esta apreciación, que puede ser cierta en los inicios del desarrollo periodístico, se queda corta, no obstante, conforme la prensa latinoamericana va madurando. La prensa, pues, no es solo un vehículo de información sobre el comercio sino que llega a ser un elemento catalizador entre cultura, mercado y poder, en un primer momento de desarrollo global de la información. En este contexto, estas alianzas cobran un carácter estratégico de representación en lo que se percibe como una lucha de discursos por la hegemonía representacional.

PRensa e identidad transnacional: DE Lo local a lo GLOBal

En 1888, apenas tres años después de publicar su novela en las páginas de El LatinoAmericano, José Martí escribió una crónica para La Nación de Buenos Aires titulada "La Republica Argentina en el exterior” donde da cuenta de una reunión de la Cámara de Comercio de Nueva York para pedir formalmente al Congreso el apoyo al establecimiento de una línea de vapores para el comercio entre EE.UU. y Argentina. A lo largo de su crónica, Martí destaca la ignorancia de la mayoría de los comerciantes neoyorquinos sobre Argentina. "No sabíamos por acá que allá, junto al otro polo, hubiese un país que nos sigue tan de cerca” (70-1) son las palabras transcritas de uno de ellos en las que no pasa desapercibida el juego de distancias, el acá y el allá, los dos polos del globo, ahora tan “cerca”. Por ello, Martí elige transcribir también el acto mismo de representación de la modernidad Argentina llevado a cabo en la Cámara por un tal Hopkins con el fin de persuadir a su audiencia: “aquella extraordinaria República, cuya estadística nos iguala, cuando no nos saca ventaja; cuyas leyes son a semejanza de las nuestras; cuya metrópoli lo es de la América del Sur, como Nueva York de la del norte; cuyo comercio con nosotros es la vigésima parte del comercio total del país, cuya altura a la de nadie envidia” (77). El propósito de Martí no es otro que el de poner de relieve las consecuencias políticas, ideológicas y económicas de este acto representacional, un gesto que, al contrario del de Wallace, el escritor cubano interpreta como contrapunto a los discursos imperiales:

Y lo notable y útil del discurso [...] fue [...] que no dijo estas cosas como de menos a más, pidiendo como merced que el águila ampare con su águila [sic] un país de aldea, según

\footnotetext{
${ }^{7}$ Términos contradictorios según la concepción de Matei Calinescu de que el arte moderno nace en oposición a la modernidad material, y según también se ha venido entendiendo el modernismo, algo que como sugiero aquí necesita revisarse.
} 
torpemente hacen algunos políticos perniquebrados; o admiradores, tan amigos de la tierra ajena que pierden el respeto por la propia. Hopkins no basó sus demandas en que la Argentina las solicitase, sino en que por su riqueza es un mercado apetecible para el comercio hipertrofiado de los Estados Unidos, y en que el progreso continuo de sus instituciones y su capacidad de desenvolverse por sí propia merece el respeto de Norte América, a quién por el empuje se compara y vence en generosidad y cortesía. (73)

José Martí, argumentando en contra del proteccionismo económico y a favor de la liberalización de los mercados, establece una correlación positiva entre representación, comercio y modernidad en tanto no se establezca una relación de desigualdad sino de beneficio mutuo entre pares, en tanto no sea un acto discursivo imperial de paternalismo e imposición. Esta crónica martiana comparte una vez más la máxima “Conocer y ser conocido" del título de El Latino-Americano. En ambos casos hay un cierto nivel de autorreferencialidad en tanto la prensa debe ser medio para esa difusión del conocimiento; es más, no sólo su vehículo sino quizás su razón misma de ser. La crónica de Martí aparecía en el más importante periódico argentino, La Nación, y la prensa, como el urbanismo o el desarrollo económico, constituía uno de los mayores índices de modernidad: “[Argentina] cuenta con periódicos como La Nación, La Prensa, y La Tribuna Nacional, que serían una honra para cualquier pueblo del globo” (77). Es este sentido del valor de la prensa y de la producción cultural como medidores de la posición de la comunidad en el "globo" el que hay que buscar en la constitución y desarrollo de la prensa latinoamericana de entre siglos.

También bajo esta óptica habría que leer "Nuestra América” cuando aparece en la Revista Ilustrada de Nueva York. Si “Nuestra América” está enmarcada por la angustia de una ofensiva que no se va a librar tanto en el campo de batalla como en el de las ideas, al texto mismo del ensayo lo domina la preocupación por la escritura y el saber. Sin duda que esta casi obsesión epistemológica de Martí tiene un propósito político de unidad continental, un arte del buen gobierno que, siguiendo la lectura ya clásica de Julio Ramos, sitúa la autoridad de lo literario en el centro de la esfera pública: "En tanto resistencia a la modernización, la literatura efectivamente armaba una defensa contra el imperialismo, contra la amenaza de “ellos”: la modernidad expansiva de los Estados Unidos y, a la vez, los discursos internamente colonizadores de los “letrados artificiales” (243). No obstante, a diferencia de lo que afirma Ramos, no se trata de una resistencia a la modernización sino de la constitución de las bases ideológicas y epistemológicas en las que la modernidad latinoamericana debía asentarse para poder participar en lo que Martí denominaba "orden universal” (11) de una manera activa y no como meros objetos de los discursos externos de otras modernidades. Para Martí, como para las revistas estudiadas en algunas de las cuales él participó activamente, el conocimiento es estrategia política de inmediatas consecuencias. Si América debe conocerse a sí misma y no vivir más como una "aldea”, debe también abrirse y darse a conocer, escribirse a sí misma para no ser escrita por otros cuyos discursos oculten y posibiliten "la codicia”, la intervención, la colonización. ${ }^{8}$

\footnotetext{
${ }^{8}$ Tanto en “Nuestra América” como en "Madre América”, la apelación a Latinoamérica está mediada por la visión desde afuera. Este cruce entre construcción identitaria y representación desde afuera también está presente en otros ámbitos de la producción cultural del momento. En la novela El hombre de hierro (1907) de Blanco Fombona, se encuentra lo siguiente: “en Europa y los Estados
} 
La prensa, nacida de la modernidad misma, era la institución perfecta para llevar a cabo este proyecto. En esta línea, la crónica, que Ramos lee en su heterogeneidad como el deseo de intervención en la esfera pública y por tanto como uno de los rasgos distintivos de la institución literaria latinoamericana, quizás lo sea pero no tanto por limitación de la autonomía de lo literario, sino por su creación de un espacio donde la literatura podía controlar la representación de lo latinoamericano y de su modernidad, al tiempo que participar de otras modernidades; los volúmenes de crónicas escritas en el periodo de entre siglos son testimonio de esta voluntad de representación del otro, sean las modernidades imperiales de EE.UU., Francia e Inglaterra, sean otras modernidades periféricas como España e Italia. Legitimación de la autoridad de la escritura hispanoamericana para definirse y definir a los demás y así contrarrestar la autoridad auto-legitimada de los poderes imperiales. ${ }^{9}$

Sin lugar a dudas que gran parte de los proyectos intelectuales y políticos analizados hasta ahora en la prensa latinoamericana editada fuera de sus fronteras geográficas, formaron parte también de los periódicos y revistas nacionales. Un caso emblemático y extremo sería el de la revista venezolana editada a fines del siglo XIX por Pedro Coll, Cosmópolis, la cual establece desde su propio título muchas de las mismas preocupaciones de sus colegas afuera: "Nosotros, hijos de la misma madre, permanecíamos desconocidos unos de otros pero ahora gracias a la literatura y a los periódicos que surgen en todas las Repúblicas españolas, nos saludamos como hermanos, nos conocemos y estamos alegres como en plena luna de miel” (citado en Aching 133). La prensa y la literatura tienen, pues, el poder -y el deber, quizás- de unir lo disperso, el “ejercicio hermanador” (232) del que habla Ramos a propósito de Martí y a partir de ahí, trascender las fronteras nacionales y articular la constitución de un entidad y de un discurso transnacionales con el que participar en la red de los nuevos discursos globales:

Unidos se hace una campaña constante de descrédito contra los pueblos hispano-americanos, por medio del telégrafo y de la Prensa, y con el plan de pintarnos a los ojos del mundo en estado completo de salvajez que disculpe todos los atropellos de que quieran hacernos víctimas”. Años más tarde en 1919, el intelectual colombiano, Sanín Cano, colaborador tanto en la Revista Ilustrada como en Mundial Magazine, le escribía a su amigo Alcides Arguedas: "Viviendo uno en Europa siente estas críticas con mayor intensidad porque los directores de la opinión y los especuladores del futuro se apoderan de ellas y las usan en contra nuestra a la primera oportunidad. [...] Ahora la Gran Bretaña está haciendo en Irlanda lo que no hizo nunca el doctor Francia, lo que no se atrevió a hacer Rosas, lo que Melgarejo ni siquiera habría imaginado que se pudiera hacer. [...] Europa ha gastado en cinco años más de 30 mil millones para destruir gran parte de las libertades políticas que se habían conquistado en un siglo. [...] ha convertido los parlamentos en farsas de arrabal, elecciones en mercados de gitanos, la prensa en un órgano de los gobiernos y los intereses creados, la industria en una especie de juego a suerte en el que los capitalistas usan dados falsos. Pero acá guardan esto en sus casas y en los archivos secretos y es mala educación (bad form) sacar a relucir tales desventuras a la calle” (297). Aún en los años 20, J.E. Rivera fundó la Editorial Andes en Nueva York porque "debemos situar puntos de referencia para conocernos y para que nos conozcan" (citado en Peña 56-57).

${ }^{9}$ Sobre el carácter epistemológico del lenguaje literario en la crónica modernista y el Modernismo en general desde perspectivas distintas pero relacionadas, véase Jrade, González, Ramos y Rotker. 
En este periódico como lo indica su nombre tendrán acogida todas las escuelas literarias, de todos los países. El cosmopolitismo es una de las formas más hermosas de la civilización pues que ella reconoce que el hombre rompiendo con preocupaciones y prejuicios, remplaza la idea de Patria por la de Humanidad. La literatura ha hecho a favor de la confraternidad humana más que todas las intrigas diplomáticas; los países más lejanos se conocen, se acercan y simpatizan por el libro y el periódico; las ideas viajan de una nación a otra sin hacer caso de los empleados de aduana, de los ejércitos fronterizos, las razas se estrechan y la paz se impone. (Citado en Aching 140)

Sin embargo, al igual que en las revistas estudiadas, se desea ser "universal” a partir de lo local: “Admito el programa siempre que vibre en él la nota criolla. ¡Regionalismo!” (140). Esta tensión entre lo nacional y lo universal es una de las tensiones definidoras del discurso finisecular de la modernidad latinoamericana, y la prensa y la literatura, sus campos de batalla.

Apelar, no obstante, a la transnacionalidad y la comunidad global desde las fronteras nacionales tenía dichas fronteras también como barreras. Al situarse en un lugar fuera, y más exactamente en un lugar asociado con el poder y la modernidad como eran Nueva York y París, esa barrera no sólo quedaba eliminada sino que además ayudaba a la construcción del imaginario comunitario como parte de la vanguardia moderna, constructor y partícipe del futuro. Así lo afirma Losada, el editor de la Revista Ilustrada de Nueva York: “[una publicación] que desde esta metrópoli del mundo, a donde llegan los ecos de todos los pueblos civilizados, dé la voz de alerta, siempre que sea necesario" (citado en Chamberlin 4). Lo mismo ocurre con el París de Mundial Magazine. Como afirma Kirsten Silva Gruess en su excelente libro Ambassadors of Culture, a propósito de las comunidades impresas latinas en Estados Unidos, parte de la razón de ser de estas publicaciones residía en "the power of print to keep the family together under the pressures of modernity" (189). La localización exterior de las revistas frente a sus colegas nacionales, continúa Gruess, "promises to tone down what would otherwise be the more powerful allegiances to specific national homelands, for in New York Spanish speakers have more in common than they have elsewhere" (189). A ello habría que añadir, al menos por lo que respecta al fin de siglo, la conciencia de que ocupar un espacio transnacional tenía en sí el poder de luchar contra emergentes reconsideraciones de centro y periferia.

Dentro de las relaciones directas entre mercado, cultura, modernidad y discursos, la prensa latinoamericana en general, y la editada en las grandes metrópolis de EE.UU. y Europa en particular, incrementa su rol no sólo como índice de modernidad sino como su vehículo mismo en tanto ofrece un espacio textual en el que la modernidad latinoamericana podía articularse. El control de este espacio representacional se convierte, pues, para los intelectuales de entre siglos en un medio para proyectar el doble alcance del "nosotros": la apelación a una unidad interna y a una modernidad posible con la que enfrentar otras modernidades posibles cuyos discursos homogeneizantes serían, como el de Wallace, una ficción destinada a justificar la intervención en la supuesta heterogeneidad del otro. ${ }^{10} \mathrm{En}$

\footnotetext{
${ }^{10}$ Se podría argumentar que los intelectuales latinoamericanos quieren enfrentar su saber al de los discursos metropolitanos con respecto a los cuales no quieren mantener una relación de subalternidad, contraponiendo lo que Walter Mignolo llama “historias locales” a los “diseños globales”, aunque no
} 
otra etapa de globalización, los escritores del anterior fin de siglo apuntaban a las alianzas entre modernidad, información y representación como tres instancias interdependientes.

BiBLIOGRAFÍA

Aching, Gerard. By Exquisite Design: The Politics of Spanish American Modernismo. Cambridge/New York: Cambridge University Press, 1997.

Anderson, Benedict. Imagined Communities. Reflections on the Origin and Spread of Nationalism. London/New York: Verso, 1991.

“Apuntes editoriales”. Editorial. El Latino-Americano [New York] 15 Sept. 1885: 24.

Blanco Fombona, Rufino. El hombre de hierro. Caracas: Ediciones Populares Venezolanas, 1907.

Calinescu, Matei. Five Faces of Modernity. Modernism, Avant-Garde, Decadence, Kitsch, Postmodernism. Durham, NC: Duke University Press, 1990.

“Conocer y ser conocido”. Editorial. El Latino-Americano [New York] 15 Jan. 1886: 152.

“Crónica mundial”. Mundial Magazine (París, 1 May 1911): 62-63.

Chamberlin, Vernon A. and Ivan A. Schulman. La Revista Ilustrada de Nueva York. History, Anthology, and Index of Literary Selections. Columbia, MO: University of Missouri Press, 1976.

García Canclini, Néstor. Consumers and Citizens. Globalization and Multicultural Conflicts. Minneapolis: University of Minnesota Press, 2001.

González, Aníbal. La crónica modernista hispanoamericana. Madrid: Porrúa Turanzas, 1983.

Gruess, Kirsten Silva. Ambassadors of Culture: the Transamerican Origins of Latino Writing. Princeton, NJ: Princeton University Press, 2002.

Hernández de López, Ana María. El Mundial Magazine de Rubén Darío. Historia, estudio e índices. Madrid: Beramar, 1989.

Jrade, Cathy L. Modernismo, Modernity, and the Development of Spanish American Literature. Austin: U of Texas P, 1998.

“La publicidad de Mundial”. Mundial Magazine (París, 1 May 1911): 109.

Martí, José. “Nuestra América”. Nuestra América. Buenos Aires: Losada, 1939. 11-23. “La República Argentina en el exterior”. Nuestra América. Buenos Aires: Losada, 1939. 69-79.

“Madre América”. Nuestra América. Buenos Aires: Losada, 1939. 25-36. Lucía Jerez. Madrid: Cátedra, 1994.

Mignolo, Walter. Local Histories/Global Designs. Coloniality, Subaltern Knowledges, and Border Thinking. Princeton: Princeton University Press, 2000.

“Mundial”. Mundial Magazine (París, 1 May 1911): 5.

Peña Gutiérrez, Isaías. Breves historia de José Eustasio Rivera. Bogotá: Magisterio, 1988. “Política y religión”. Editorial. El Latino-Americano (New York, 1 Nov. 1885): 72.

habría que olvidar que el "nosotros" letrado no es inclusivo con respecto a otros discursos subalternos latinoamericanos. 
“¿Quiénes son los americanos?” Editorial. El Latino-Americano (New York, 15 Jan. 1886): 152.

Rama, Ángel. Rubén Darío y el modernismo. Caracas: Ediciones de la Biblioteca de la Universidad Central de Venezuela, 1970.

La ciudad letrada. Hanover, NH: Ediciones del Norte, 1984.

Ramos, Julio. Desencuentros de la modernidad en América Latina. Literatura y política en el siglo XIX. México DF: Fondo de Cultura Económica, 1989.

Rotker, Susana. Fundación de una escritura: las crónicas de José Martí. Habana: Casa de las Américas, 1991.

[Sanín Cano] Arguedas, Alcides. Epistolario de Alcides Arguedas. La generación de la amargura. La Paz: Fundación Manuel Vicente Ballivián, 1979. 